\title{
Does patient education in rheumatoid arthritis have therapeutic potential?
}

\author{
Marian Tucker, John R Kirwan
}

Rheumatoid arthritis (RA), a common and serious condition, can be viewed as a model for chronic disease in general. In addition to its chronic nature, RA is characterised by uncertain disease progression and an unpredictable course of exacerbations and remissions. While there is as yet no cure, there is evidence that various medical interventions may ameliorate its effects. In addition, the management of RA often results in the patient coming into contact with a large number and variety of health professionals and in learning complex physical and medical therapeutic regimens. For many patients their pain, disability, deformity, and reduced quality of life persist in spite of treatment. There is clearly room for new approaches to enhance current treatment effectiveness. Patient education is one such approach that is thought by many to be beneficial in helping patients to cope and cooperate with their disease and its complex management. ${ }^{1-4}$

There has been increasing research in the field of patient education, and major reviews of published studies have been conducted by Mazzuca on the value of education in chronic disease in general $^{5}$ and more recently by Mullen $^{6}$ and Lorig on education in arthritis. ${ }^{7}$ In the current climate of rising health care costs and audit it is important to justify the effectiveness of patient education. Thus it may be useful to distinguish between patients' 'right' to know more about their disease and its management and the health benefit they might receive from increased knowledge. Many would argue that patients do have an inherent right to information, and studies have shown that patients do want to know about their illness, ${ }^{8-10}$ but this in itself does not imply that education should be automatically included in management. Like other interventions it should be viewed in terms of its efficacy and adverse effects. If beneficial effects can be shown then it should be recognised that patients do have a need to know for the sake of their health, and education should be regarded as part of routine management. This paper reviews some published patient education programmes and critically analyses whether patient education in arthritis can yet be justified in therapeutic terms.

Rheumatology Unit, University Department of Medicine, Bristol Royal Infirmary, Bristol BS2 8HW $M$ Tucker J R Kirwan Correspondence to: Dr Kirwan

Justifying education programmes

Green defines patient education as including all planned educational activities aimed at assisting patients in achieving voluntary health behaviour changes. ${ }^{11}$ It assumes the acquisition of knowledge, skills, and attitudes in order to effect these changes. Education programmes
Table 1 Questions to ask when assessing a patient education programme

Are the educational objectives appropriate?

Are the educational methods appropriate?

Have the educational objectives been achieved?

Has there been therapeutic benefit?

Are there adverse effects?

What is the resource cost?

can be assessed as outlined in table 1. These assessments relate, firstly, to the internal educational coherence of the objectives of the programme, the methods used to attain them, and their success; and, secondly, to the achievement of the external standard of therapeutic benefit measured in clinical rather than educational terms. This potential effect of education on disease outcome is of prime concern to both patients and health care providers. Trying to discover if there has been improvement in health status and quality of life as a result of taking part in an educational programme has often been beyond the scope of many published reports, partly because the time taken to show such effects is prohibitive and partly because of failure to perceive the need to show explicit therapeutic efficacy. When it is not possible to evaluate therapeutic outcome the attainment of educational objectives which seem appropriate may provide at least some guide to likely efficacy.

\section{A review of some published programmes}

ARE THE EDUCATIONAL OBJECTIVES APPROPRIATE? Owing to the complex nature of RA and its management and because no one course of treatment has proved to be consistently effective, the objectives of patient education programmes have shown wide variation. Table 2

Table 2 Knowledge, skills, and attitudes considered in patient education programmes

\section{Knowledge}

Disease process and medical management ${ }^{4} 1415172829$ Drugs 41415172628

Nutrition 414152829

Exercise/joint protection 41415172829

'Quackery'/alternative treatments' 152829

Community resources ${ }^{14}$

Skills

Skills $4 \quad 14 \quad 28$ 45-48 57

Joint protection/energy conservation/work simplification ${ }^{14}$

Relaxation/stress

Drugs $^{4} 14$ is 1588
Attitudes

Coping

Problem solving/goal setting ${ }^{46} 50$

Stress management

Self efficacy

Self esteem ${ }^{6}$ 
shows some of the major areas considered. This list is not exhaustive but represents those objectives most commonly reported in published studies. One of the key components in developing an education programme is that the content should be based on the needs and beliefs of those receiving education, ${ }^{79} 1012$ enabling new information to be built on to and into these existing beliefs. Divergence of opinions between patients and health providers about the importance of various aspects of the disease, its management, and treatment has been clearly shown. ${ }^{910}{ }^{13}$ Formulating an agreed agenda between the patient and the educator is therefore clearly essential. Mazzuca suggests that patients do not need to know about the pathophysiology of their disease, ${ }^{5}$ but in a study by Silvers patients themselves rated pathophysiology and diagnostic procedures as very important. ${ }^{10}$ The importance of considering measures to reduce pain and disability is generally accepted as the highest priority, but it is not surprising that there is a variation in needs and beliefs when different cultures, customs, races, and geographical settings are studied. This re-emphasises the importance of recognising these factors when formulating a suitable curriculum. Only Lindroth, ${ }^{14}$ Goeppinger, ${ }^{15}$ and Lorig ${ }^{16}$ report that they have assessed patient needs when designing their education programmes.

It is necessary to consider the appropriateness of and justification for the various educational objectives included in the programmes. Poor levels of knowledge have been noted in patients before the start of education. ${ }^{14} 17$ This is often in the face of a long disease history and patient experience of regular contact with health professionals. Williams and Wood suggest that this lack of understanding of the medical model of illness is not ignorance on the part of patients, but rather that they have their own well constructed but non-medical models of illness. ${ }^{18}$ The implication here is that knowledge should not only make sense scientifically but should also fit into a valued framework of patients' life events on which is based their own illness explanation. Although many programmes emphasise medical knowledge, there is in fact little evidence to support a causal link between knowledge, behaviour, and health outcome. If a better informed patient is the aim of the programme then almost all are successful in the short term, ${ }^{7}$ with the improvement maintained for up to two and a half years in one long term study. ${ }^{19}$ Programmes concentrating on gains in knowledge alone are rarely successful in improving health, however. ${ }^{5}$

Skills and behaviours thought to be beneficial in arthritis are a second major component of education. There are many skills widely held as being of therapeutic value and those most commonly included in programmes are listed in table 2. Evidence from controlled trials to support their therapeutic value is weak and in some cases non-existent.

Exercise is commonly taught and is a routine part of management, yet few studies have been conducted in this field. A recent study did show a reduction in the number of swollen joints with no adverse effects for patients with moderately active RA undergoing aerobic training. ${ }^{20}$ An uncontrolled trial on quadriceps exercises for osteoarthritic knees demonstrated improved function, ${ }^{21}$ but whether this is also true for patients with RA is not known.

Relaxation is another common practice and has been shown to produce significant pain relief in patients with osteoarthritis, ${ }^{22}$ but again evidence that relaxation in RA is consistently efficacious is inconclusive. Many relaxation methods require a person to rest physically in order to practise relaxation, and rest itself has a beneficial effect. Randomised controlled trials by Randich ${ }^{23}$ and Shearn ${ }^{24}$ showed no improvement in pain in patients practising relaxation techniques.

Instruction in joint protection is another intuitively sensible part of management, but here again the evidence for its success is weak. A review by Agnew concludes that the effects of joint protection on pain and stress, inflammation, and the prevention of deformities have yet to be shown. ${ }^{25}$

The therapeutic effects of drugs are well reported, but it is the question of cooperation or compliance with drug regimens ${ }^{3}$ which is of importance in education programmes. In one study only six of 32 patients with early RA reported taking the number of tablets prescribed by their general practitioners. ${ }^{9}$ Drug information leaflets combined with verbal advice as a method of improving knowledge and compliance have been tested and gains in knowledge reported. ${ }^{26}$

Attitudinal objectives have recently attracted more attention and are coming to be regarded by some as important variables in the outcome of disease. Health professionals and patients in general disagree about the importance of the psychosocial content of education. Although depression, ${ }^{13}$ 15 fear and anxiety, ${ }^{13}$ self awareness, ${ }^{14}$ communication skills, ${ }^{10} 14$ and stress management ${ }^{14}$ have all been cited by patients as topics for inclusion in education programmes, they are considered to be of much lower importance than pain and disability. ${ }^{10} 13$ The logic of RA suggests that psychosocial consequences of arthritis are likely to be secondary to the biologically obvious effects of pain and disability. It seems reasonable, therefore, to argue that programmes which focus solely or primarily on psychosocial factors may have inappropriate objectives.

\section{ARE THE EDUCATIONAL METHODS APPROPRIATE?}

As important as the content of a programme are the various processes and methods by which it is presented. Table 3 lists some of the approaches

Table 3 Teaching methods used for patient education

\section{Small group work
Individual teaching}

Computer assisted instruction

Didactic

Interactive

Lay-led groups

Home study

Passive instructional (booklets, audio-visual programmes) Reinforced 
used. Work in the field of adult education has shown that an interactive learning approach is more acceptable and successful than a didactic style, particularly when working with mixed ability groups. ${ }^{727}$ This has been confirmed in chronic disease ${ }^{5}$ and arthritis. ${ }^{7}$ There is little difference in effectiveness between lay-led groups and professional-led groups. ${ }^{28}$ Computer based education $^{29}$ and home study methods ${ }^{30}$ show promising results but need further investigation. Although an individual approach is an effective method of gaining knowledge, ${ }^{17}$ small group work is more effective at changing attitudes and behaviours. ${ }^{12}$ Investigations of the routine provision of information leaflets ${ }^{26} 3132$ have only examined gains in knowledge. Rather surprisingly, a reinforcement programme which provided 'refresher courses' for patients did not show any improvement over the gains made during the initial education programme. ${ }^{33}$

\section{HAVE THE EDUCATIONAL OBJECTIVES BEEN} ACHIEVED?

In one review $94 \%$ of studies measuring changes in knowledge demonstrated improvement, ${ }^{7}$ suggesting that most programmes are competent at teaching patients facts. In most studies changes in skills are evaluated by self report of behaviours, assuming that patients have been using their skills correctly and as frequently as they say. Budesheim et al did, however, ask patients to demonstrate their skills. ${ }^{34}$ Although the actual use of skills is of greater importance than the ability to demonstrate them, unless the skills are checked as part of the assessment method it cannot be assumed that they are performed correctly. Given this reservation, $77 \%$ of studies measuring changes in selfreported behaviour showed increased use of skills. Instruments (questionnaires) have been

Table 4 Effects of rheumatoid arthritis on quality of life

\begin{tabular}{ll}
\hline Dimension & Size of $R A$ effect \\
\hline Mortality & + \\
$\begin{array}{l}\text { Discomfort } \\
\text { Physical }\end{array}$ & ++ \\
$\begin{array}{c}\text { Mental } \\
\text { Disability }\end{array}$ & $+/-$ \\
$\quad$ Physical & ++ \\
Mental & - \\
Costs & + \\
\hline
\end{tabular}

developed to explore the various psychological aspects of arthritis ${ }^{21}{ }^{35-37}$ and have been used to assess patients. Success in changing attitudes is less consistent than for knowledge and skills, though more than half of the studies measuring the achievement of attitudinal objectives showed improvement. ${ }^{7}$ Outcomes for coping (managing to continue with life despite the difficulties of illness), anxiety, and self efficacy (belief in the ability personally to do things which improve illness) were more positive than those for depression and loss of control.

\section{HAS THERE BEEN THERAPEUTIC BENEFIT?}

Therapeutic benefit shown by an improvement in the 'quality of life' must remain the final arbiter of efficacy. Table 4 outlines one convenient classification of the main effects of RA on different dimensions of a person's quality of life. Although measures of disease activity using a variety of clinical tests are sometimes used to assess the results of education programmes, it is of greater importance to measure the effects on those variables that directly impinge on a person with arthritis. Particular attention should be paid to the aspects which are affected to a greater degree by RA-physical discomfort (pain) and disability.

No attempt has yet been made to measure alterations in mortality in RA as a result of patient education, yet educational achievement has been shown to be a strong predictor of subsequent mortality. ${ }^{38}$

Pain, joint count, morning stiffness, and global health scores can all be used as measures of physical discomfort, pain being the most important. A number of studies (outlined in table 5) have reported pain reduction after educational intervention. Others have failed to show these improvements, ${ }^{1424}{ }^{39}$ including one study $^{28}$ which was based on the Arthritis Self Management Course, ${ }^{40}$ adopted by the Arthritis Foundation for use throughout the United States. In a study by Parker an increase in pain was reported after traditional patient education. ${ }^{39}$ These inconsistent findings may in part be explained by the shortcomings of the assessment tools employed, ${ }^{41}$ but it has been argued that pain may not be an optimal measure for assessing the effectiveness of patient education. ${ }^{14}$

Table 5 Studies showing pain reduction by patient education

\begin{tabular}{|c|c|c|c|}
\hline Author & Study design & Measure & Intervention \\
\hline Bradley $e t a f^{2}$ & $\begin{array}{l}\text { Randomised and controlled } \\
\text { with testing before and after }\end{array}$ & Visual analogue scale (VAS) & $\begin{array}{l}\text { Biofeedback. } \\
\text { Cognitive-behavioural } \\
\text { group therapy }\end{array}$ \\
\hline Lorig $e t a l^{4}$ & $\begin{array}{l}\text { Randomised and longitudinal } \\
(20 \text { months) }\end{array}$ & Ordinal scale & Arthritis self-management course \\
\hline Lorig et $a l^{55}$ & Randomised, controlled, & VAS and ordinal scale & Arthritis self-management course \\
\hline Minor $e t a l^{45}$ & $\begin{array}{l}\text { Randomised, controlled, } \\
\text { longitudinal (12 weeks) }\end{array}$ & Not known & Physical conditioning, exercise \\
\hline O'Leary $e t a l^{50}$ & $\begin{array}{l}\text { Randomised, controlled, } \\
\text { testing before and after }\end{array}$ & Not known & $\begin{array}{l}\text { Cognitive behavioural training in } \\
\text { coping techniques, relaxation, } \\
\text { pain strategies, and goal setting }\end{array}$ \\
\hline Perlman $e t a l^{46}$ & $\begin{array}{l}\text { Test of } 3 \text { groups before } \\
\text { and after }\end{array}$ & AIMS* & $\begin{array}{l}\text { Low impact aerobic dance/exercise } \\
\text { and problem solving education }\end{array}$ \\
\hline Goeppinger et $a l^{15}$ & $\begin{array}{l}\text { Randomised, controlled, } \\
\text { longitudinal (12 months) }\end{array}$ & $\begin{array}{l}\text { Composite score using VAS, } \\
\text { ordinal scale, and Gracely } \\
\text { pain scale }\end{array}$ & $\begin{array}{l}\text { Small group lay-led arthritis } \\
\text { self-care intervention }\end{array}$ \\
\hline
\end{tabular}

${ }^{*}$ AIMS = arthritis impact measurement scales. 
Pain may act as the limiting factor to normal daily activities, so that the final result of a programme might be to increase function within the same pain threshold. Although there may be many beneficial outcomes from an educational programme other than pain relief, it remains the most important concern of patients with arthritis. ${ }^{7914}$ Thus it should surely be assessed either in terms of a person's perception of pain or their ability to control pain.

Results of studies of the impact of RA on a person's psychological status (mental discomfort) are not consistent ${ }^{5158-60}$ and caution is required when judging the success of patient education interventions in affecting these variables. When studies do measure psychological status an improvement is often shown. More recent results suggest that there is little difference in psychological status between patients with RA and those with other chronic diseases, ${ }^{42}$ but factors such as perceived helplessness, social support, and self efficacy are important mediators in patient education and predictors of future disability and pain..$^{30} 4344$ Physical disability measures include functional assessments, physical assessments, walking time, and grip strength. In the 76 programmes reviewed by Lorig $^{7} 45$ measures of physical disability were reported, of which 27 showed improvement. In an additional study patients reported increased functional ability one year after completing an education programme. ${ }^{14}$ Programmes emphasising exercise and physical training have consistently shown improvements in physical health status. ${ }^{45-48}$ Only one study by Achterberg $e t$ al reported negative findings after education. ${ }^{49}$ Other characteristics of programmes successful in improving function were those emphasising problem solving, ${ }^{48}$ selfmanagement activities, ${ }^{14}{ }^{16}$ coping, ${ }^{50}$ and self efficacy. ${ }^{50}$ Other studies have, however, failed to show positive outcomes for physical status. ${ }^{15} 24283957$ It might be further argued that given the progressive nature of $R A$, the absence of a decline in function may be interpreted as evidence of programme success. ${ }^{7} 30$ Furthermore, reports have not yet considered the possibility that although potential function remains unchanged, actual function-that is, the degree to which patients use their potential, might have improved.

\section{ARE THERE ADVERSE EFFECTS?}

Possible adverse effects after education have not been well reported. It has been suggested that for patients with a recent onset of chronic illness information may lead to increased depression. ${ }^{9}$ Heightened levels of helplessness and fear are other potential reactions. ${ }^{53}$ Where the content of a programme does not relate to the beliefs of the group or individual confusion may result. ${ }^{9}$ Fostering a misplaced sense of personal responsibility for the development and care of their arthritis may be potentially harmful, and education as a substitute for standard medical care should be avoided. ${ }^{53}$ Attempts to encourage changes in lifestyle, work practices, and psychosocial variables may also have detrimental effects on both personal and work relationships.
WHAT IS THE RESOURCE COST?

For patient education to justify its place as a routine part of patient management requires proof of its cost effectiveness. Although many studies suggest beneficial therapeutic and subjective improvements, they are presented in a way which makes it difficult to quantify their financial balance. The cost of providing an education programme is often omitted from reports and a subsequent reduction in the demand for health service resources has yet to be shown. Measures that might be assessed include: the number of visits to doctors; hospital admissions; paramedic treatment; and drug use. In addition, changes in lost income or in social support might be included. In one study the number of visits to a doctor was reduced by $35 \%$ over 20 months of follow up. ${ }^{33}$ Although outcome cost savings are difficult to measure, input costs can be estimated. For most programmes the major cost is health professional time per patient and of those studies that report either time or number of patients in each group, the average cost is about 12 hours per programme or one and a half hours per patient. In the United Kingdom this is about $£ 12$ per patient based on current senior paramedic/nurse salary scales. This figure rises when programmes are individualised to two and a half hours per patient $(£ 20)$. Where programmes concentrate on objectives such as stress and pain management, coping strategies, and relaxation there is a further increase ranging from 10 to 80 hours per programme, but information on group size has not been provided and comparative costs cannot be calculated. In some programmes costs can be reduced by the use of trained lay leaders ${ }^{28} 30$ and home study methods. Although capital costs may be high, computer based education subsequently requires little input from professionals. At present the cost of providing education must be viewed as additional expenditure but when placed in the context of other medical expenses, even minor therapeutic benefit would make it cost effective.

\section{Summary of review}

Rheumatoid arthritis is associated with a severe negative health status having major adverse effects on individual patients and society as a whole. ${ }^{42}$ Although the therapeutic efficacy of many currently used treatments still needs to be better established, patient education has been shown to enhance these treatments, as judged by improved knowledge and behaviour. Improvements in pain and function are less consistent. The mechanisms by which education works are still not fully understood. ${ }^{55}$ Those programmes which have been shown to have beneficial outcomes in influencing health status $^{14-1646-48505455}$ have the following characteristics:

- They are related to the needs and beliefs of the patients taking part

- They emphasise the relief of pain and disability

- They use interactive teaching methods in group settings 
Table 6 Information required to assess reports about patient education

Aims and objectives of programme

Teaching methods used

Overall study design

Patient population

Evaluation instruments

Sample size

Concurrent treatments

Resource costs

Adverse effects

- They develop self-management techniques, problem solving, and self efficacy

- They employ exercise training.

Clearly many of the reports reviewed above do not include sufficient information on which to base an adequate assessment of the utility of the education programmes which they advocate. Table 6 lists the main areas which should be included in future reports. A randomised, controlled, longitudinal trial is probably the best overall study design, though alternatives have been proposed. ${ }^{7}$ About one third of the 64 RA education studies reviewed by Lorig were controlled and randomised. In view of the relation between patients' background and their educational needs, patient selection is an important aspect of programme assessment. The best patient sample will be representative for sex, disease duration, functional status, socioeconomic status, and education level. Nonrepresentative groups have often been usedfor example, one sample comprised low income male veterans who had had their arthritis for 14 years and were of a low education level, ${ }^{56}$ while another was predominantly female with a disease duration of less than five years and high educational achievement. ${ }^{29}$ The use of validated assessment instruments is particularly important when measuring psychosocial variables as many scales are not designed to be used in the presence of somatic complaints such as those of arthritis. Sample size should be appropriate to that required to detect clinically useful effects, and few reports include details of concurrent treatments. When education is only one part of a multidisciplinary team management any changes in drugs, use of paramedical services,

Table 7 Objectives of the Bristol patient education programme

By the end of the programme the patient will:

Knowledge

1 Describe the variable nature of rheumatoid arthritis

Explain the effects, side effects, and regimens of the drugs they are taking for arthritis

Explain the simple principles of exercise for mobility and strength

Understand that people with arthritis get anxious and depressed, that this is variable, and that there are ways of coping with these feelings

there are ways of coping with these feelings

6 Know that there is a list of agencies/individuals to contact for help for their arthritis and related

kroblems

8 Describe the features of a chair most appropriate for their condition

Skills

9 Demonstrate the use of hot/cold treatment safely

10 Demonstrate principles of joint protection using a tap, and other everyday objects

11 Demonstrate exercises for mobility and strength in the knee and one other appropriate joint

12 Design a daily programme which incorporates rest and activity

13 Demonstrate correct self medication

Attitudes

14 Believe they can reduce their pain by adopting self help techniques

15 Believe that adopting changes in their lifestyle and environment will be beneficial

16 Feel less anxious and depressed

17 Feel more in control and other treatments for both control and experimental groups should be reported. In short, to justify the therapeutic benefit of new innovations in education the same standards should apply as those used for other therapeutic manoeuvres. Many researchers in this field are now aware of these problems and randomised controlled studies are being adopted. ${ }^{15} 162428394750$ Work on refining measurements of such variables as pain, disability, self efficacy, helplessness, coping, and social support is continuing.

\section{Current attempts to promote patient} education in the United Kingdom

Most reports on the education of patients with arthritis have been published by workers in the United States and, more recently, in Australia. Because of differing cultural and social circumstances, health care systems, and patient ascertainment it is difficult to apply these findings directly to a United Kingdom population or to use some of the available educational materials appropriately. Only two of the studies reviewed were conducted in the United Kingdom ${ }^{26} 31$ and both had limited and specific objectives. This does not, however, indicate a lack of interest or activity in the United Kingdom, but rather a failure to evaluate, record, and publish those projects which have been undertaken Our own (far from exhaustive) personal inquiries have disclosed developing or operating programmes soundly based on the assessment of patient needs and the use of appropriate adult education methods in four cities (Salisbury, Bath, Leeds, and Newcastle), all directed towards the alleviation of symptoms. The development of a patient education programme in Bristol illustrates one approach.

The programme was designed for patients with acute flares of their RA who were admitted to a small eight-bedded rheumatology ward for bed rest, assessment, re-evaluation of treatment, physiotherapy, and occupational therapy review. Pilot studies were performed to gauge the knowledge, skills, and attitudes of these patients, and showed their preoccupation with pain relief by drugs, their low level of 'medical' knowledge, and their feelings of anxiety, depression, and loss of control of their lives. Based on the published material available (reviewed above), the advice of experts in mental health and adult education, and the results of the pilot studies, a patient education programme was devised considering the objectives shown in table 7. The aim of the programme is to provide basic knowledge, practical skills, and appropriate attitudes which will help patients with RA to improve their function, reduce their pain, reduce their use of health service resources, and take greater control over their lives. It is hoped that these benefits will manifest themselves over the months and years after the education programme. The course consists of seven group sessions, many individual patient interview or instruction sessions, and the ward self-medication scheme. It accommodates the need for many patients to rest in bed during their first week in hospital, and 
allows a number of topics to be introduced on a personal basis before they are dealt with in group sessions. It requires a commitment of 11 hours a week from the programme organiser but has almost no other resource requirements.

The programme has been implemented as part of a separately funded research project which aims to test if the patient education programme fulfils its educational objectives in the short term; to test the feasibility and practicality of running the programme successfully as part of routine inpatient management; to discover if it is acceptable to both patients and staff; and to assess the resources that would be required for continuing implementation of the programme. To evaluate the effectiveness of the programme the ability of patients to meet the objectives is tested at the beginning and end. The tests include a multiple choice questionnaire, interviews, the demonstration of skills, the Hospital Anxiety and Depression (HAD) Scale, and the Arthritis Helplessness Index.

Although this is a small uncontrolled study, preliminary results are encouraging and suggest that moderate but definite improvements occur in most patients' knowledge, skills, and attitudes. Should the final results confirm this impression then the patient education programme should be subject to a controlled trial.

\section{Moving forward}

In addition to the general need for evaluation of implemented or proposed education programmes, there are a number of specific issues which need to be considered. Is it possible to identify those patients most likely to benefit from education? At what stage in the disease process should we intervene-would too much education too early in the disease be counterproductive? What setting-for example, inpatients with a flare up or outpatients in a community setting when they are in less painis most conducive or practical? Can we provide more clear cut evidence from controlled trials to establish which exercises and joint protection practices have greatest therapeutic value? What are the most cost effective methods of delivering patient education?

We expect that as the enthusiastic specific interest groups for nursing and the paramedical professions in rheumatology develop and the medical profession offers increasing recognition and support for patient education these questions will be considered, and education will be able to make an effective contribution to the management of people with arthritis.

Ms Tucker and the development and testing of the Bristol patient education programme were supported by the Bristol and Weston Health Authority and the Arthritis and Rheumatism Council.

1 Brooks P M, Lindroth Y. Patient education in chronic arthritis. Med f Aust 1985; 143: 486-7.

Fries J. Management of early RA-a symposium report. Scand $\mathcal{f}$ Rheumatol 1988; 17: 307-10.

3 Jette A. Improving patient co-operation with arthritis treatment regimens. Arthritis Rheum 1982; 25: 447-53.

4 Lorig K, Lubeck D, Kraines R G, Seleznick M, Holman H R. Outcomes of self-help education for patients with arthritis. Arthritis Rheum 1985; 28: 680-5.
5 Mazzuca S A. Does patients education in chronic disease have therapeutic value? f Chronic Dis 1982; 35: 521-9.

6 Mullen P D, Laville E A, Biddle A K, Lorig K. Efficacy of psycho-educational interventions on pain, depression and disability in people with arthritis: a metaanalysis. F Rheumatol 1987; 14 (suppl 15): 33-9.

7 Lorig K, Konkol L, Gonzalez V. Arthritis patient education a review of the literature. Patient Education Counsel 1987; 10: 207-52.

8 Potts $M$, Weinberger $M$, Brandt $K$. Views of patients and providers regarding the importance of various aspects of an arthritis treatment programme. $\mathcal{F}$ Rheumatol 1985; 12 907-12.

9 Donovan J L, Blake D R, Fleming W G. The patient is not a blank sheet: lay beliefs and their tolerance to patient education. Br f Rheumatol 1989; 28: 58-61.

10 Silvers I J, Hovell M F, Weisman M H, Mueller M R. Assessing physician/patient perceptions in rheumatoid Assessing physician/patient perceptions in

11 Green L W, Krueler M, Partridge K B, Deeds S G. Health education planning: a diagnostic approach. Calif. Mayfield: Palo, 1979.

12 Ewles L, Simnett I. Promoting health-a practical guide to health education. London: Wiley, 1987.

13 Lorig K, Cox T, Cuevas Y, Kraines R G, Britton M C Converging and diverging beliefs about arthritis: Caucasian patients, Spanish-speaking patients and physicians. f R heumatol 1984; 11: 76-9.

14 Lindroth Y, Bauman A, Barnes C, McCredie M, Brooks $\mathrm{P}$ M. A controlled evaluation of arthritis education. $\mathrm{Br} \mathcal{J}$ Rheumatol 1989; 28: 7-12.

15 Goeppinger J, Brunk S E, Arthur M W, Reidesel S. The effectiveness of community-based arthritis self-care programmes [Abstract]. Arthritis Rheum 1987; 30 (suppl): gramm.

16 Lorig K, Feigenbaum P, Regan C, Ung E, Holman H R. A comparison of lay taught and professional taught arthritis self-management course. $\mathcal{f}$ R heumatol 1986; 13: 763-7.

17 Lorish C D, Parker J, Brown S. Effective patient education: quasi-experiment comparing an individual strategy with a routinised strategy. Arthritis Rheum 1985; 28: 1289-97.

18 Williams G H, Wood P H N. Patients and their illnesses: common sense beliefs about illness-a mediating role for the doctor. Lancet 1986; ii: 435-7.

19 Parker J C, Hazelwood S, Hall P, Hewett J, Singsen B. Patient education in rheumatoid arthritis: a long term follow-up [Abstract]. Arthritis Rheum 1983; 26 (suppl): S83.

20 Lyndberg K, Danneskiold-Samsoe B, Halskov O. The effect of physical training on patients with rheumatoid arthritis changes in disease activity, muscle strength and aerobic capacity. Clin Exp Rheumatol 1988; 6: 260.

21 Chamberlain M A, Care G, Harfield B. Physiotherapy in osteoarthritis of the knees. A controlled trial of hospita versus home exercises. Int Rehabil Med 1982; 4: 101-6.

22 Laborde J M, Powers M J. Evaluation of educational interventions for osteoarthritis. Multiple Linear Regression Viewpoints 1983; 12: 12-37.

23 Randich S R. Evaluation of a pain management programme for rheumatoid arthritis patients [Abstract]. Arthritis Rheum 1982; 25 (suppl): S11.

24 Shearn M A, Fireman B. Stress management and mutual support groups in rheumatoid arthritis (RA): a controlled support groups in rheumatoid arthritis
study. Am $\mathcal{F}$ Med 1985; 78: 771-5.

25 Agnew P J. Joint protection in arthritis: fact or fiction? British Fournal of Occupational Therapy 1987; 50: 227-30.

26 Punchak S S, Kay E A. Educating arthritis patients about their drugs. Pharmaceutical fournal 1988; 238: 247-9.

27 Rogers J. Adults learning. Milton Keynes: Open University Press, 1977.

28 Cohen J L, Van Houten S, De Vellis R F, McEvoy S, De Vellis B. Evaluation of arthritis self management courses led by lay persons and professionals. Arthritis Rheum 1986; 29: 388-93.

29 Wetstone S L, Sheehan T J, Votow R, Petersen M, Rothfield $\mathrm{N}$. Evaluation of a computer based education (CBE) lesson $N$. Evaluation of a computer based education (CBE) lesson
for patients with rheumatoid arthritis. $\mathcal{J}$ Rheumatol 1985 ; 12: $907-12$.

30 Goeppinger J, Arthur M W, Baglion Jr A J, Brunk S E, Brunner $C M$. A re-examination of the effectiveness of selfcare education for persons with arthritis. Arthritis Rheum 1989; 32: 706-16.

31 Moll J H N. The cartoon in doctor-patient communication. Ann Rheum Dis 1977; 36: 225-31.

32 Vignos $P$ J, Parker W T, Thompson $H$ M. Evaluation of a clinical education programme for patients with rheumatoid arthritis. I Rheumatol 1976; 3: 155-65.

33 Lorig K, Holman H R. Long-term outcomes of an arthritis self-management study: effects of reinforcement efforts. self-management study: effects
Soc Sci Med 1989; 29: 221-4.

34 Budesheim G C, Black S O, Vogel K, Hassenien R. $A$ comparison of the relative effects of self-instruction, contracting and practice on knowledge of complicance to an arthritis treatment regimen [Abstract]. Arthritis Rheum 1987; 30 (suppl): S207.

35 Zigmond A S, Snaith R P. The hospital anxiety and depression scale. Acta Psychiatr Scand 1983; 67: 361-70.

36 Meenan R F, Gertman P M, Mason J H. Measuring health status in arthritis. The Arthritis Impact Measurement Scales. Arthritis Rheum 1980; 23: 146-52.

37 Chambers L W, Macdonald L A, Tugwell $P$, Watson Buchanan W, Kraag G. The McMaster Health Index Questionnaire as a measure of quality of life for patients with rheumatoid disease. $\mathcal{F}$ Rheumatol 1982; 9: 780-4. 
38 Pincus T. Formal educational level-a marker for the importance of behavioural variables in the pathogenesis, morbidity and mortality of most diseases. $\mathcal{f}$ Rheumatol 1988; 15: 1457-60.

39 Parker J C, Singsen B, Hewett J, et al. Educating patients with rheumatoid arthritis: prospective analysis. Arch Phys with rheumatoid arthritis: pros

40 Lorig K. Arthritis self-management leaders manual. Atlanta: Arthritis Foundation, 1984

41 Badley E M, Papageorgiou A. Visual analogue scales as measure of pain in arthritis: a study of overall pain and pain in individual joints at rest and on movement. $\mathcal{F}$ Rheumatol 1989; 16: 102-5.

42 Mason J H, Weener J L, Gertman P M, Meenan R F. Health status in chronic disease: a comparative study of rheumatoid arthritis. F Rheumatol 1983; 10: 763-8.

43 Nicassio $M$ P, Wallston $K$ A, Callahan $L F$, Herbert $M$ Pincus T. The management of helplessness in RA: the development of the arthritis helplessness index. I R heumatol 1985; 12: 462-7.

44 Lorig K, Chastain R L, Ung E, Shoor S, Holman H R. Development and evaluation of a scale to measure perceived Development and evaluation of a scale to measure perceived 32: $37-44$.

45 Minor M A, Hewett J E, Kay D R. Monitoring for harmful effects of physical conditioning exercise (PCE) with arthritis patients [Abstract]. Arthritis Rheum 1986; 29 (suppl): S144

46 Perlman S G, Connell K, Alberti J, Conlon P, Clark A Synergistic effects of exercise and problem-solving education for RA patients [Abstract]. Arthritis Rheum 1987; 30: (suppl): S194.

47 Banwell B, Lampman R, Cabral A, Castor C W, Versteeg $M$. A comparison of aerobic versus flexibility training in rheumatoid arthritis [Abstract]. Arthritis Rheum 1984; 27 (suppl): S130.

48 Perlman S G, Connell K, Alberti J, Coulon P, Mueller $M$ Exercise and problem-solving education programme for Exercise and problem-solving education programme for
rheumatoid arthritis [Abstract]. Arthritis Rheum 1985; 28 (suppl): S148.

49 Achterberg J, McGraw P, Lawlis G P. Rheumatoid arthritis: study of relaxation and adjunctive therapy. Biofeedback Self Regul 1981; 6: 207-16.

50 O'Leary A, Shoor S, Lorig K, Holman H R. A cognitive(reatment for rheumatoid arthritis. Health Psychol (in press).

51 Nalven F B, O'Brien J F. Personality patterns of rheumatoid arthritis patients. Arthritis Rheum 1964; 7: 18-28.

52 Bradley L A, Young L D, Anderson K O, et al. Effects of psychological therapy on pain behaviour of rheumatoid arthritis patients: treatment outcome and six month followup. Arthritis Rheum 1987; 30: 1105-14.

53 Holman $\mathrm{H}$, Lorig $\mathrm{K}$. Patient education in the rheumatic diseases-pros and cons. Bull Rheum Dis 1987; 37: 5

54 Bradley L A, Young L D, Anderson K O, McDaniel L K, Turner R A, Agndelo C A. Psychological approaches to the management of arthritis pain. Soc Sci Med 1984; 19 1353-60.

55 Lorig K, Seleznick M, Lubeck D, Ung E, Chastain R L, Holman $H R$. The beneficial outcomes of the arthritis selfmanagement course are not adequately explained by manaviour change. Arthritis Rheum 1989; 32: 91-5.

56 Parker J C, Frank R G, Beck N C, et al. Pain management in rheumatoid arthritis patients: a cognitive behavioural rheumatoid arthritis patients: a cognitive
approach. Arthritis Rheum 1988; 31: 593-601.

57 Wineland M, Zische J, Dennis G, Klipple G. The physical and psychological effects of a recreational exercise program on persons with rheumatoid arthritis and osteoarthritis [Abstract]. Arthritis Rheum 1985; 28 (suppl): S139.

58 Murphy S, Creed F, Jayson M. Psychiatric disorders and illness behaviour in rheumatoid arthritis. Br $\mathcal{F}$ Rheumatol 1988; 27: 357-63.

59 Hawley D, Wolfe F. Anxiety and depression in patients with rheumatoid arthritis: a prospective study of 400 patients. 7 Rheumatol 1988; 15: 926-31.

60 McFarlane A C, Brooks P M. An analysis of the relationship between psychological morbidity and disease activity in retween psychological morbidity and disease activity

61 Kaplan S, Kozin S. A controlled study of group counselling in rheumatoid arthritis. $\mathcal{f}$ Rheumatol 1981; 8: 91-9. 